\title{
Response of Posidonia oceanica growth to dredging effects of different magnitude
}

\author{
Giuseppe Di Carlo ${ }^{1, *}$, Lisandro Benedetti-Cecchi ${ }^{2}$, Fabio Badalamenti ${ }^{1}$ \\ ${ }^{1}$ Laboratorio di Ecologia Marina, IAMC-CNR, Via G. da Verrazzano 17, 91014 Castellammare del Golfo (TP), Italy \\ ${ }^{2}$ Dipartimento di Biologia, Università di Pisa, CoNISMa, Via Derna 1 56126, Pisa, Italy
}

\begin{abstract}
The response of the seagrass Posidonia oceanica in an area physically disturbed by 2 dredging events was evaluated to understand the recovery time of this species and compared to 2 reference locations. An asymmetrical 'beyond BACI' (Before/After, Control/Impact) sampling design was applied in combination with reconstructive techniques to compare vertical rhizome elongation and leaf production in $P$. oceanica during $4 \mathrm{yr}$ before and $4 \mathrm{yr}$ after each dredging event in 1 disturbed and 2 reference locations. On average, vertical rhizome elongation increased from before to after each dredging event, with higher growth being recorded in the disturbed location compared to the reference locations. This effect appeared to be driven by a combination of the application of different dredging techniques and exposure to prolonged stress, as rhizomes had not completely recovered from the first impact by the time the second, lower magnitude disturbance occurred. No difference in leaf production was found. This work highlights the importance of disturbance history and dredging method in determining the response of $P$. oceanica to multiple disturbances, and provides insights into the recovery time of the seagrass when repetitive effects to the same meadow occur. This becomes particularly relevant as infrastructure development continues to expand along the world's coastline and seagrasses are challenged with the exponential increase of physical disturbance.
\end{abstract}

KEY WORDS: Posidonia oceanica · Dredging · Recovery · Reconstruction methods • 'Beyond BACI' design $\cdot$ Mediterranean Sea

\section{Resale or republication not permitted without written consent of the publisher}

\section{INTRODUCTION}

As human population continues to grow, pressures on the coastal zone continue to increase with resulting negative effects on coastal habitats, including seagrass beds (Orth et al. 2006). Particularly, the expansion and maintenance of coastal infrastructure, such as harbours, channels and pipelines, involves the disposal of unconsolidated materials (i.e. dredged sand), which is often conducted in the proximity of sensitive habitats (Duarte 2002, Erftemeijer \& Lewis 2006). This process not only causes the modification of the coastal area and its physical dynamics, but also the loss of high-value ecosystem services and ecological functions provided by seagrass beds. Recent evidence has indicated a global trajectory of decline for seagrasses with a current loss rate of about $9 \% \mathrm{yr}^{-1}$ (Waycott et al. 2009).
Estimates of the economic value of seagrass ecosystem services are in the order of US\$ $19004 \mathrm{ha}^{-1} \mathrm{yr}^{-1}$ (Costanza et al. 1997, Duarte et al. 2008), although this number varies widely among bioregions (Short et al. 2007). While this is a global issue, it is particularly relevant for the Mediterranean region, where high-value ecosystem services are mostly provided by a single seagrass species, Posidonia oceanica. In this scenario, it becomes critical to understand the recovery dynamics, including the temporal scale, of $P$. oceanica to physical stressors and its response to repeated disturbances.

In the Mediterranean Sea, Posidonia oceanica (L) Delile is the dominant, endemic seagrass species. This slow-growing species, whose vertical rhizomes may live $>30 \mathrm{yr}$, is particularly sensitive to environmental disturbance; hence it is considered to be a biological sentinel of marine coastal waters (Duarte 1991, Per- 
gent-Martini \& Pergent 1995, Marbà et al. 1996). $P$. oceanica responses to several different mechanical and physical effects have been described in a number of studies (Guidetti \& Fabiano 2000, Ruiz \& Romero 2003, Erftemeijer \& Lewis 2006). However, there is still a paucity of knowledge on the recovery time of $P$. oceanica to physical disturbance (i.e. dredging), since few studies have shown any post-disturbance recovery of this species.

Previous studies (see Guidetti 2001, Peirano 2002) approached the response of Posidonia oceanica to environmental disturbance by assessing variation in annual leaf production and elongation rate of vertical rhizomes, as these parameters reflect changes in the environmental features (e.g. changes in sedimentation rates) during the lifespan of vertical seagrass shoots. This method is particularly effective in P. oceanica, as the changes over time of both annual leaf production and rhizome elongation may be reconstructed from the analysis of some persistent morphological features of reiterative modules (sheaths and internodes) on which seagrass growth is based (Duarte et al. 1994). To detect significant changes in a given variable, this method compares the potentially affected location before and after the disturbance, and compares these results with those obtained from multiple reference locations (Underwood 1993, Guidetti 2001).

When applied in combination with specific experimental asymmetrical designs, adopted to detect single point-source impacts (Underwood 1992, 1993), such as the 'beyond BACI' (Before/After, Control/Impact) design, these reconstructive techniques represent a powerful tool. This approach can be used to evaluate the response of Posidonia oceanica to physical disturbance (Guidetti 2001, Peirano 2002, Montefalcone et al. 2008), and has demonstrated its potential in assessing the response of seagrass to physical disturbance, especially when pre-effect data is lacking. However, no attempts have been made to use this approach to assess the response of $P$. oceanica to multiple effects occurring at the same location over a different time scale and the consequent recovery time for this species.

The goal of this study was to assess the response of Posidonia oceanica to repeated anthropogenic effects of different magnitudes by reconstructing past changes in leaf production and vertical rhizome elongation. Disturbances were originated by 2 dredge-fill events, which created sediment plumes and consequently altered sedimentation rates, causing high patch mortality in the meadow surrounding the dredged area (Badalamenti et al. 2006). Based on the results of previous studies (Guidetti 2001, Badalamenti et al. 2006), we hypothesized a significant increase in leaf production and vertical rhizome elongation rate from before to after the 2 periods of disturbance, in an affected location in the proximity of a dredged area.

\section{MATERIALS AND METHODS}

Study site and sampling design. Between 1982 and 1993 a gas pipeline connecting Algeria, Tunisia and ultimately Italy was constructed. This operation is considered the largest marine infrastructure development in the Mediterranean Sea and required the removal of $\sim 150$ ha of seagrass as well as physically disturbing the adjacent Posidonia oceanica meadow by pulsed siltation (Di Carlo et al. 2005, Badalamenti et al. 2006). In 1982, the first dredging event severely damaged the seagrass meadow, as a result of invasive dredging technologies, which included the use of explosives. The second dredging event in 1993 resulted in a similar disturbance, although the effect was minimized due to the application of modern dredging techniques (Badalamenti et al. 2006). Thus, the 2 effects occurred over a 12-yr time scale, representing disturbance events of different magnitudes.

In spring 1999, vertical shoots of Posidonia oceanica were sampled at Capo Feto (SW Mediterranean Sea, Italy) at a depth of $8 \pm 3 \mathrm{~m}$. Samples from the disturbed location were collected at a distance of 30 to $50 \mathrm{~m}$ from the dredged area. Two locations on the nearby P. oceanica meadow (located $1500 \mathrm{~m}$ away from the dredged area) were sampled at the same depth and used as reference locations reflecting relatively pristine conditions (Badalamenti et al. 2006, Di Carlo et al. 2007). Six vertical shoots were haphazardly collected from each of 32 sites (tens of metres apart) at each location (32 sites $\times 6$ replicas $\times 3$ locations $=576$ samples $)$. We chose shoots that were long enough to allow a retrospective analysis of elongation and leaf production (see next section). As P. oceanica is a clonal plant (Procaccini et al. 2001), shoots were collected at a minimum distance of tens of metres apart to avoid collecting more than one sample from the same horizontal rhizome. Shoots at each site contributed only to data for a particular year of interest (see next section). This was achieved by distributing the 32 sites across 6 shoots for 4 yr for each time period (before/after) at 3 locations (disturbance and 2 references) for 2 disturbance events.

Laboratory analysis. Internodal length of vertical shoots was measured using a binocular microscope at $60 \times$ magnification, after removal of old leaf sheaths (Duarte et al. 1994, Marbà \& Duarte 1997). In seagrasses, internodes show a clear seasonal variation in length. Long internodes are produced at the end of the summer, whilst short ones are produced during the winter (Marbà \& Duarte 1997). Since seagrass shoots 
grow following the production of new internodes, the youngest one is close to the apical meristem and the oldest is located next the horizontal rhizome. Thus, annual leaf formation (number of leaves $\mathrm{yr}^{-1}$ ) and the annual rhizome elongation $\left(\mathrm{mm} \mathrm{yr}^{-1}\right)$ can be estimated on the basis of the annual cycles in length of vertical internodes (Duarte et al. 1994). Moreover, the 1:1 relationship between leaf and vertical internode allows the number of vertical internodes between 2 consecutive minima in length to be used as a surrogate for the number of leaves produced during a time period (Guidetti 2001). Following this procedure, vertical internodal length was obtained for each vertical shoot analysed, and annual rhizome elongation rate was calculated as the sum of length increments of internodes produced within a year by each shoot. Estimates of the leaf formation and rhizome elongation from 1978 to 1997 were obtained and these data are compared to assess environmental effects. From the data set, the year of effect occurrence was discarded (1982 and 1993) as well as the 2-yr period (1987 and 1988) between the two 8-yr assessment periods. In addition, the last 2 yr of plant growth were discarded (1998 and 1999) as rhizome elongation cycle is considered to take 2 to 3 yr before complete lignification (Peirano 2002).

Data analysis. Differences in mean number of leaves and mean length of vertical rhizomes from before to after each of the 2 periods of disturbance were examined using multilevel mixed effect models (Singer \& Willet 2003, McMahon \& Diez 2007), at the disturbed and reference locations. A classical application of these analytical techniques is in longitudinal studies where repeated observations are made on the same sampling or experimental units, resulting in temporally autocorrelated data. Mixed effect models take autocorrelation into account and enable great flexibility in modelling multiple sources of random variation in hierarchical designs. An example of the use of mixed effect models in the analysis of human effects on growth of Posidonia oceanica is provided by Tomasello et al. (2007). Our data were temporally independent at the scale of the rhizome and site (we allocated different rhizomes and sites to the measurement of different years), but not at the scale of location. So, we used a mixed effect analysis consisting of a level-1 sub-model to account for possible sources of temporal autocorrelation within locations and a level-2 sub-model to test for fixed effects including: (1) period of human intervention $(P$, with 2 levels, 1981 and 1993), (2) the condition before vs. after the disturbance in each period $(B A),(3)$ the contrast between disturbed and reference locations $(D)$ and the 1-way and 2-way interactions among these effects. The level 1 sub-model was:

$$
Y_{i j k r}=\pi_{0 i}+\pi_{1 i} \text { Year }_{i k}+u_{i j k}+\varepsilon_{i j k}
$$

where $Y_{i j k r}$ is the response variable (length of rhizomes or number of leaves) corresponding to location $i$, site $j$, observation unit $r$ and year $k_{i}$ and $\pi_{0 i}$ and $\pi_{1 i}$ are the true intercept and linear trajectory of annual change of individual location $i$, respectively, and $u_{i j k}$ and $\varepsilon_{i j k r}$ are the level-1 residuals reflecting the random effects of site $j$ and observation unit $r$ (in location $i$ and year $k$ ), respectively. The level-2 sub-model included:

$$
\begin{gathered}
\pi_{0 i}=\gamma_{00}+\gamma_{01} P_{i}+\gamma_{02} B A_{i}+\gamma_{03} D_{i}+\gamma_{04} P x B A_{i}+ \\
\gamma_{05} P x D_{i}+\gamma_{06} B A x D_{i}+\gamma_{07} P x B A x D_{i}+\phi_{0 i} \\
\pi_{1 i}=\gamma_{10}+\phi_{1 i}
\end{gathered}
$$

where $\gamma_{00}$ and $\gamma_{10}$ are the level-2 intercept and slope describing population average values of level-1 coefficients $\pi_{0 i}$ and $\pi_{1 i}$, when the levels of predictor variables are at 0 , respectively, and the other $\gamma$ 's describe the effects of period of disturbance $P_{i}$, the condition before vs. after $B A_{i}$ the effect of disturbance $D_{i}$ and their interactions on level-1 coefficients; $\phi_{0 i}$ and $\phi_{1 i}$ are the level-2 residuals, allowing the intercept and slope of the location of $i$ to deviate from population averages.

The stochastic component of the model assumed that level-1 residuals were normally distributed with mean 0 and variance $\sigma_{u}^{2}$ and $\sigma_{\varepsilon}^{2}$ for sites and observation units, respectively, while the level-2 residuals were assumed to be multivariate normal with unknown random parameters reflecting the variance among locations in intercept $\left(\sigma^{2}{ }_{L}\right)$, slope $\left(\sigma^{2}{ }_{Y}\right)$ and the covariance between intercept and slope $\left(\sigma_{L Y}^{2}\right)$ in year to year variation.

The multilevel model was fitted with Restricted Maximum Likelihood (REML) using function lmer in package lme4 of R 2.10.1 (R Development Core Team 2010). The significance of individual regression coefficients was tested using the Wald test (Singer \& Willet 2003). The significance of variance components (except $\sigma_{\varepsilon}^{2}$ ) was assessed through Likelihood Ratio tests (LR) comparing the full model (Eqs. 1-2) with a reduced model that did not include the specific component (Singer \& Willet 2003).

\section{RESULTS}

Rhizome vertical elongation did not differ between disturbed and reference locations before the first human intervention (1978 to 1981, Fig. 1). A 2-fold increase in rhizome elongation rate occurred at the disturbed location compared to undisturbed ones after the first human intervention in 1982 (Figs. 1 \& 2). This effect persisted for a period of about 4 yr (1983 to 1986), after which rhizome internodal length decreased in the disturbed location, although remaining well above values observed in the references (1989 to 1992, Fig. 1). The second human intervention induced a response in 
rhizome elongation that was qualitatively similar to the one observed for the first disturbance, but lower in magnitude (1994 to 1997, Fig. 2). These patterns were supported by the results of the mixed effect statistical model (Table 1). The significant and positive coefficient associated with the $B A \times D$ interaction indicated that, on average, vertical rhizome elongation rate increased from before to after human intervention in the disturbed compared to the reference locations over the 2 periods. The significant and negative coefficient associated with the $P \times B A \times D$ interaction indicated that the response of rhizomes was less dramatic in the second disturbance than in the first one (Table 1, Fig. 2). This was in part a consequence of the fact that rhizome internodal length was already higher in the disturbed location compared to the references before the onset of the second intervention (Fig. 2). Variance components indicated that spatial variation in rhizome length was large and significant at the scale of site.

In contrast to vertical rhizome elongation, annual leaf production did not show any significant response to either disturbance event (Fig. 3). There was a nonsignificant increase in annual leaf production in the disturbed location after the first human intervention (Fig. 3). This increase was negligible although the $B A \times D$ interaction apparently reflected this effect (with $0.1<\mathrm{p}<$ 0.05). Variance components were negligible and not significant for annual leaf production.

\section{DISCUSSION}

The results presented here confirm the plasticity of Posidonia oceanica growth modules and how environmental variability at the local scale can induce a

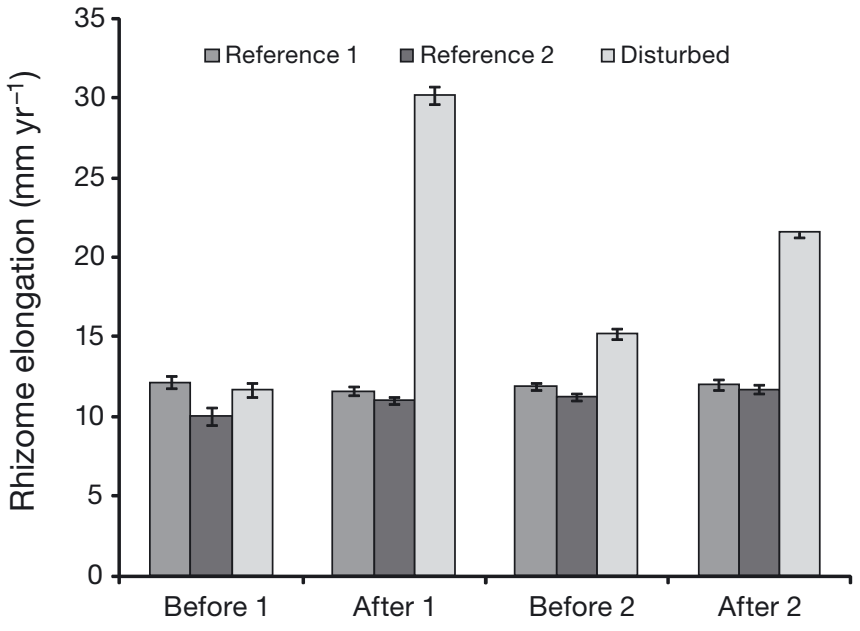

Fig. 2. Posidonia oceanica. Effects of disturbance on rhizome vertical growth. Mean values $( \pm \mathrm{SE}, \mathrm{n}=48$ ) for $4 \mathrm{yr}$ periods before and after 2 disturbance events, from 1 disturbed and 2 reference locations. Before 1 and After 1 refer to the first,

Before 2 and After 2 to the second period of disturbance

response in $P$. oceanica rhizome growth. Similar evidence was provided by Marbà et al. (1996) reporting how $P$. oceanica population dynamics and growth varied according to the Spanish Mediterranean coastal climate. In our study, vertical rhizome elongation increased up to $3.1 \mathrm{~cm} \mathrm{yr}^{-1}$ in response to the first dredging event in 1982, a value that falls within the range observed (1.2 to $5.9 \mathrm{~cm} \mathrm{yr}^{-1}$ ) following the input of terrigenous discharge along the Spanish Mediterranean coast (Marbà et al. 1996). Rhizomes continued to sustain a higher growth rate for $4 \mathrm{yr}$ after the effect (see Fig. 1), before growth was significantly reduced. Although vertical rhizome elongation largely decreas-

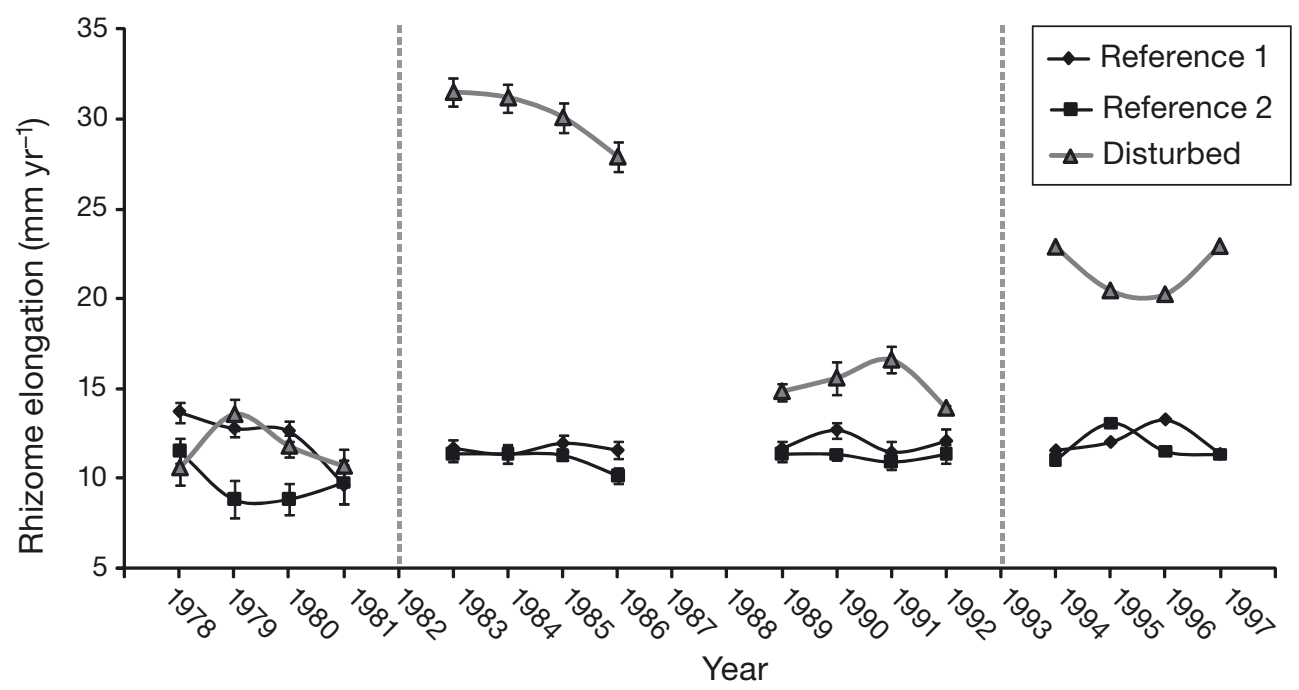

Fig. 1. Posidonia oceanica. Rhizome elongation $\mathrm{yr}^{-1}(\mathrm{mean} \pm \mathrm{SE})$ at 1 disturbed and 2 reference locations, before and after 2 disturbance events (1982 and 1993) at Capo Feto (Sicily, Italy) 
Table 1. Posidonia oceanica. Parameter estimates and significance tests from mixed effects models fitted to vertical rhizome elongation and leaf formation. SE: standard error; ns: not significant. Random effects are variance components reflecting differences among locations in intercept $\left(\sigma_{L}^{2}\right)$, slope $\left(\sigma^{2}{ }_{Y}\right)$ and the covariance between intercept and slope $\left(\sigma^{2}{ }_{L Y}\right)$ in year to year variation; variance estimates at smaller spatial scales include differences among sites $\left(\sigma^{2}{ }_{u}\right)$ and residual variance $\left(\sigma^{2}{ }_{e}\right)$. Variance components $<1 \times 10^{-5}$ were set to zero

\begin{tabular}{|c|c|c|c|c|c|c|}
\hline \multirow[b]{2}{*}{ Effects } & \multicolumn{3}{|c|}{ — Vertical rhizome elongation -} & \multicolumn{3}{|c|}{$\longrightarrow$ Leaf production } \\
\hline & Coefficient & SE & $\mathrm{p}$ & Coefficient & SE & $\mathrm{p}$ \\
\hline \multicolumn{7}{|l|}{ Fixed effects } \\
\hline Intercept & 24.24 & 6.818 & $<0.001$ & 7.153 & 0.111 & $<0.0001$ \\
\hline Period $=P$ & 3.333 & 1.023 & $<0.001$ & -0.104 & 0.13 & ns \\
\hline Before vs. After $=B A$ & 7.144 & 0.568 & $<0.0001$ & 0.028 & 0.13 & ns \\
\hline Disturbed vs. Reference $=D$ & 2.111 & 4.821 & ns & 0.028 & 0.078 & ns \\
\hline$P \times B A$ & -3.837 & 0.526 & $<0.0001$ & -0.174 & 0.183 & ns \\
\hline$P \times D$ & 1.298 & 0.723 & ns & -0.052 & 0.092 & ns \\
\hline$B A \times D$ & 6.219 & 0.402 & $<0.0001$ & 0.163 & 0.092 & ns \\
\hline$P \times B A \times D$ & -4.036 & 0.372 & $<0.0001$ & -0.142 & 0.13 & ns \\
\hline \multicolumn{7}{|l|}{ Random effects } \\
\hline$\sigma_{L}^{2}$ & 0.0734 & & ns & 0.012 & & ns \\
\hline$\sigma_{Y}^{2}{ }_{Y}$ & 0.0512 & & ns & 0 & & ns \\
\hline$\sigma_{L Y}^{2}$ & 0 & & ns & 0 & & ns \\
\hline$\sigma_{u}^{2}{ }_{u}^{L Y}$ & 0.7353 & & $<0.002$ & 0.0577 & & ns \\
\hline$\sigma_{e}{ }^{u}$ & 5.285 & & & 0.8622 & & \\
\hline
\end{tabular}

ed after 1986, internodal length never returned to preeffect values (range 1.0 to $1.1 \mathrm{~cm} \mathrm{yr}^{-1}$ ), suggesting that the stress related to dredge-fill operations affected $P$. oceanica growth for several years after the disturbance. This is confirmed by the findings noted by Badalamenti et al. (2006), showing high shoot mortality and low recruitment rate, especially in the immediate proximity of the dredged area and in deeper water. It could be inferred that the meadow was affected by a prolonged light limitation, high sedimentation and sediment re-deposition events possibly due to the resuspension of disposed dredging material and barge overflow (Erftemeijer \& Lewis 2006). The effects of the altered sediment dynamics in the area eventually caused the fragmentation of the meadow into patches, altering community structure (Vega Fernandez et al.
2005). Our results suggest that prolonged post-impact stress - as highlighted by persistent larger growth rates of rhizomes in the disturbed compared to the reference locations after the first intervention - might have concurred to determine a less dramatic effect of the second disturbance, as reflected by the significant $P \times B A \times D$ interaction in the analysis.

In addition to exposure to a previous effect, differences in dredging techniques between 1982 (explosives) and 1993 (mechanical trenching) could also explain the reduced response of vertical rhizome elongation to the second disturbance. As modern techniques became available, and continued to improve over the years, dredge-fill effects to seagrass meadows are greatly reduced, with benefits to the meadow surrounding the effect site as the disposal of

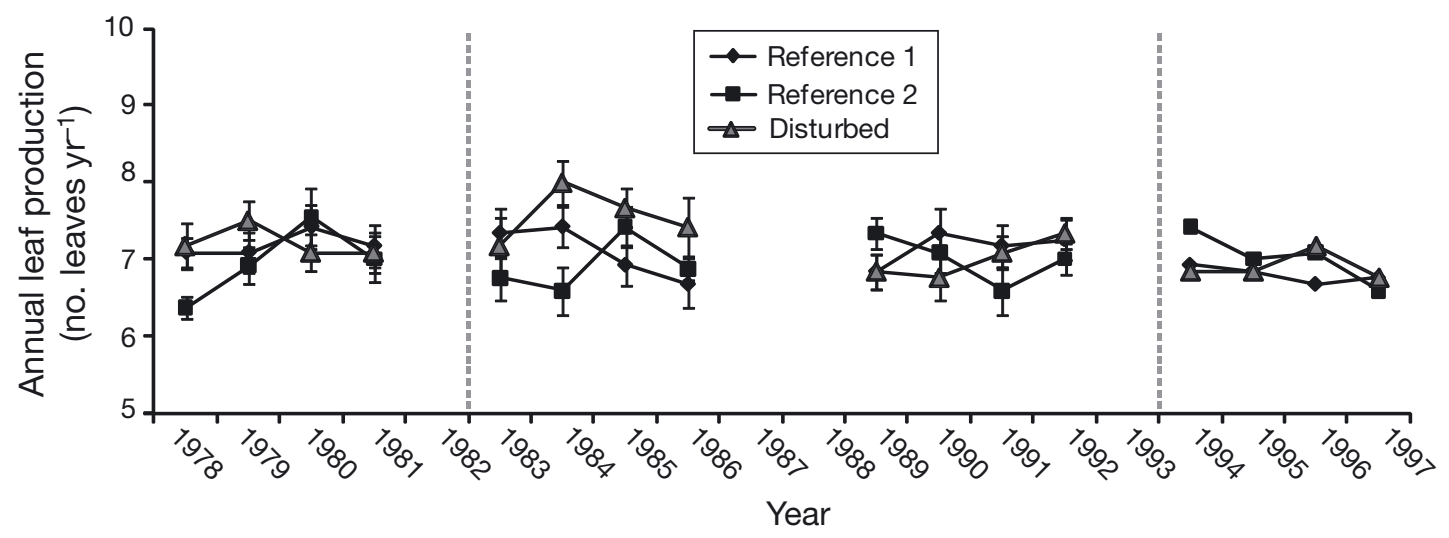

Fig. 3. Posidonia oceanica. Leaf production $\mathrm{yr}^{-1}$ (mean $\pm \mathrm{SE}$ ) at 1 disturbed and 2 reference locations, before and after 2 disturbance events (1982 and 1993) 
dredging material and sediment plumes are also minimized. At our study site, evidence on reduced effect of modern dredging techniques is provided by the smaller increase of vertical rhizome growth observed at the disturbed location after the second intervention compared to the first (Fig. 1).

It should be noted that the results presented here showed no significant differences in Posidonia oceanica leaf production from before to after either effects. This is in contrast with the findings of Guidetti (2001), who reported a reduction in leaf production as a response to the input of terrigenous material along the Ligurian coast, with no detectable increase in vertical rhizome elongation rate. While it is difficult to discuss why no change in leaf production was found in our study, it has been reported before how aboveground metrics are not always a good indicator of seagrass response to environmental variation (Di Carlo \& Kenworthy 2008).

From a methodological point of view, much has been written on positive (Duarte et al. 1994, Marbà et al. 1996) and negative (Jensen et al. 1996, Tomasello et al. 2007) aspects of reconstructive techniques. However, in light of our results, we agree that the internodal length method is a useful approach for assessing Posidonia oceanica response to environmental variation, when pre- effect data is lacking. While in some cases, the response signal may be difficult to interpret, we could identify the exact dates of the dredging events; therefore we could confidently attribute seagrass response to the dredging disturbance. This approach becomes particularly powerful when applied in combination with 'beyond BACI' design (Guidetti \& Fabiano 2000, Guidetti 2001). In this study, we applied this rigorous statistical approach for the first time to repetitive effects to a $P$. oceanica meadow. This approach provided insights on how seagrass response to environmental cues is proportional to the magnitude of the putative effects. Moreover, the results highlighted how induced stress from sediment disturbance in P. oceanica has prolonged effects (Manzanera et al. 1998).

In conclusion, the results of this paper confirm that (1) Posidonia oceanica is a good indicator of ecosystem change in response to mechanical effects that induce physical disturbances, and (2) reconstructive techniques in combination with 'beyond $\mathrm{BACI}^{\text {' designs are }}$ powerful tools to assess the effects of disturbances on $P$. oceanica meadows, especially when disturbance events can be pinpointed in space and time. This study also provides useful insights on the recovery time of $P$. oceanica when repetitive effects to the same meadow might occur. In consideration of the exponential increase of human use of the coastal zone for living space, transportation, recreation and food production, impacts to seagrass beds in the Mediterranean Sea are no longer a purely local concern and loss rates might be expected to increase in the future. In this scenario, it is critical to understand the response of seagrass ecosystems to environmental change, and the potential recovery times following physical and mechanical disturbance. Therefore, a priority for management and mitigation should be the assessment of the extent of such impacts and the implementation of more appropriate measures that take into account the resilience and recovery time of seagrasses.

Acknowledgements. The authors thank M. Coppola and P. Di Stefano for help with laboratory work. We are also grateful to M. J. Anderson, M. J. Durako, and 4 anonymous reviewers for their constructive criticism of the manuscript.

\section{LITERATURE CITED}

Badalamenti F, Di Carlo G, D'Anna G, Gristina M, Toccaceli M (2006) Effects of dredging activities on population dynamics of Posidonia oceanica (L.) Delile in the Mediterranean Sea: the case study of Capo Feto (SW Sicily, Italy). Hydrobiologia 555:253-261

> Costanza RR, d'Arge R, de Groot R, Farber S and others (1997) The value of the world's ecosystem services and natural capital. Nature 387:253-260

> Di Carlo G, Kenworthy WJ (2008) Evaluation of aboveground and belowground biomass recovery in physically disturbed seagrass beds. Oecologia 158:285-298

Di Carlo G, Badalamenti F, Jensen A, Koch E, Riggio S (2005) Colonisation process of vegetative fragments of Posidonia oceanica (L.) Delile on rubble mounds. Mar Biol 147: 1261-1270

> Di Carlo G, Badalamenti F, Terlizzi A (2007) Recruitment of Posidonia oceanica on rubble mounds, substratum effects on biomass partitioning and leaf morphology. Aquat Bot $87: 97-103$

Duarte CM (1991) Allometric scaling of seagrass form and productivity. Mar Ecol Prog Ser 77:289-300

Duarte CM (2002) The future of seagrass meadows. Environ Conserv 29:192-206

> Duarte CM, Chiscano CL (1999) Seagrass biomass and production: a reassessment. Aquat Bot 65:159-174

Duarte CM, Marbà N, Agawin N, Cebrian J and others (1994) Reconstruction of seagrass dynamics: age determination and associated tools for the seagrass ecologist. Mar Ecol Prog Ser 107:195-209

Duarte CM, Dennison WC, Orth RJ, Carruthers TJB (2008) The charisma of coastal ecosystems. Estuar Coast 31: 233-238

Erftemeijer PLA, Lewis RR (2006) Environmental impacts of dredging on seagrasses: a review. Mar Pollut Bull 52: 1553-1572

Guidetti P (2001) Detecting environmental impacts on the Mediterranean seagrass Posidonia oceanica (L.) Delile: the use of reconstructive methods in combination with 'beyond BACI' design. J Exp Mar Biol Ecol 260:27-39

> Guidetti P, Fabiano M (2000) The use of lepidochronology to assess the impact of terrigenous discharges on the primary leaf production of the Mediterranean seagrass Posidonia oceanica. Mar Pollut Bull 40:449-453

Jensen SL, Robbins BD, Bell SS (1996) Predicting population decline: seagrass demographics and the reconstructive technique. Mar Ecol Prog Ser 136:267-276 
Manzanera M, Perez M, Romero J (1998) Seagrass mortality due to oversedimentation: an experimental approach. J Coast Conserv 4:67-70

Marbà N, Duarte CM (1997) Interannual changes in seagrass (Posidonia oceanica) growth and environmental changes in the Mediterranean littoral zone. Limnol Oceanogr 42: $800-810$

Marbà N, Cebrián J, Enríquez S, Duarte CM (1996) Growth patterns of Western Mediterranean seagrasses: speciesspecific responses to seasonal forcing. Mar Ecol Prog Ser 133:203-215

McMahon SM, Diez JM (2007) Scales of association: hierarchical linear models and the measurement of ecological systems. Ecol Lett 10:437-452

Montefalcone M, Chiantore M, Lanzone A, Morri C, Bianchi CN, Albertelli G (2008) BACI design reveals the decline of the seagrass Posidonia oceanica induced by anchoring. Mar Pollut Bull 56:1637-1645

Orth RJ, Carruthers TJB, Dennison WC, Duarte CM and others (2006) A global crisis for seagrass ecosystems. Bioscience 56:987-996

Peirano A (2002) Lepidochronology and internodal length methods for studying Posidonia oceanica growth: are they compatible? Aquat Bot 74:175-180

Pergent-Martini C, Pergent G (1995) Impact of a sewage treatment plant on the Posidonia oceanica meadow: assessment criteria. Proc 2nd Int Conf on the Mediterranean Coastal Environment MEDCOAST 95:1389-1399

Procaccini G, Orsini L, Ruggiero MV, Scardi M (2001) Spatial patterns of genetic diversity in Posidonia oceanica, an endemic Mediterranean seagrass. Mol Ecol 10:1413-1421

R Development Core Team (2010) R: a language and environ-

Editorial responsibility: Just Cebrian,

Dauphin Island, Alabama, USA ment for statistical computing. R Foundation for Statistical Computing, Vienna

Ruiz JM, Romero J (2003). Effects of disturbances caused by coastal constructions on spatial structure, growth dynamics and photosynthesis of the seagrass Posidonia oceanica. Mar Pollut Bull 46:1523-1533

> Short FT, Carruthers TJB, Dennison WC, Waycott M (2007) Global seagrass distribution and diversity: a bioregional model. J Exp Mar Biol Ecol 350:3-20

Singer JD, Willett JB (2003) Applied longitudinal data analysis: modeling change and event occurrence. Oxford University Press, New York, NY

Tomasello A, Calvo S, Di Maida G, Lovison G, Pirrotta M, Sciandra M (2007) Shoot age as a confounding factor on detecting the effect of human-induced disturbance on Posidonia oceanica growth performance. J Exp Mar Biol Ecol 343:166-245

> Underwood AJ (1992) Beyond BACI: the detection of environmental impacts on populations in the real, but variable, world. J Exp Mar Biol Ecol 161:145-178

- Underwood AJ (1993) The mechanisms of spatially replicated sampling programmes to detect environmental impacts in a variable world. Aust J Ecol 18:99-116

- Vega Fernandez T, Milazzo M, Badalamenti F, D'Anna G (2005) Comparison of the fish assemblages associated with Posidonia oceanica after the partial loss and consequent fragmentation of the meadow. Estuar Coast Shelf Sci 65: $645-653$

- Waycott M, Duarte CM, Carruthers TJB, Orth RJ and others (2009) Accelerating loss of seagrasses across the globe threatens coastal ecosystems. Proc Natl Acad Sci USA 106:12377-12381

Submitted: March 9, 2010; Accepted: November 17, 2010

Proofs received from author(s): February 3, 2011 